Cahiers universitaires d'information sur l'Autriche

Finis Austriae : la chute de l'aigle bicéphale

\title{
Ralf Hoffrogge, Sozialismus und Arbeiterbewegung in Deutschland und Österreich. Von den Anfängen bis 1914
}

Jean-Numa Ducange

\section{(2) OpenEdition}

\section{Journals}

Édition électronique

URL : http://journals.openedition.org/austriaca/488

DOI : 10.4000/austriaca.488

ISSN : 2729-0603

Éditeur

Presses universitaires de Rouen et du Havre

\section{Édition imprimée}

Date de publication : 1 décembre 2018

Pagination : 290-291

ISBN : 979-10-240-1354-1

ISSN : 0396-4590

\section{Référence électronique}

Jean-Numa Ducange, «Ralf Hoffrogge, Sozialismus und Arbeiterbewegung in Deutschland und

Österreich. Von den Anfängen bis 1914 », Austriaca [En ligne], 87 | 2018, mis en ligne le 22 juillet 2020,

consulté le 30 janvier 2021. URL : http://journals.openedition.org/austriaca/488 ; DOI : https://doi.org/ 10.4000/austriaca.488

Ce document a été généré automatiquement le 30 janvier 2021.

Austriaca. Cahiers universitaires d'information sur l'Autriche 


\title{
Ralf Hoffrogge, Sozialismus und Arbeiterbewegung in Deutschland und Österreich. Von den Anfängen bis 1914
}

\author{
Jean-Numa Ducange
}

\section{RÉFÉRENCE}

Ralf Hoffrogge, Sozialismus und Arbeiterbewegung in Deutschland und Österreich. Von den Anfängen bis 1914, Stuttgart, Schmetterling-theorie.org, 240 p., ISBN : 978-3-89657-691-0, $12 €$.

1 La deuxième édition de cette synthèse sur l'histoire de la social-démocratie allemande mérite attention : elle intègre en effet, contrairement à la première, l'Autriche. Certes le propos demeure très centré sur l'Allemagne et l'Autriche n'est pas intégrée dans le corps du texte, reléguée dans un chapitre spécifique à la fin de l'ouvrage. Mais malgré cela l'association des deux espaces donne à penser les spécificités du mouvement social-démocrate germanophone d'avant 1914 hors du seul cadre de l'Allemagne sous hégémonie prussienne, ce qui n'est que trop rarement fait dans les ouvrages traitant de ce sujet depuis 1945 .

2 L'auteur commence par présenter un panorama historiographique au cours duquel il rappelle l'enjeu majeur pendant la guerre froide de cette histoire, tant dans les deux Allemagnes qu'en Autriche. Certaines figures de la première moitié du xix siècle comme Wilhelm Weitling ont circulé dans les deux espaces (de Hambourg à Leipzig, puis de la Saxe à Vienne...), montrant la forte interaction originelle. Pourtant Hoffrogge passe à côté d'un élément majeur, à peine évoqué : pour de nombreux socialistes, le rêve d'une "grande Allemagne" démocratique et républicaine réunissant tous les peuples germanophones devait à court terme devenir une réalité tangible. Quelques grands thèmes sont ensuite abordés, en intégrant des problématiques contemporaines (questions coloniales et multiethniques, genre, etc.). On souligne notamment les propos 
d'August Bebel contre les discriminations à l'égard des homosexuels, sans oublier les questions les plus classiques qui monopolisèrent longtemps l'attention des acteurs et de l'historiographie (réforme vs. révolution, démocratie, divisions - à relativiser désormais - entre marxistes et lassalliens, etc.). L'historien insiste sur la naissance d'une tradition de gauche radicale (die andere Arbeiterbewegung) dont l'expression politique, à une large échelle, sera la création du KAPD en 1921 (scission "gauchiste " du KPD). Il souligne également le rôle de l'histoire sociale pour mieux écrire une Alltagskultur des pratiques militantes (par exemple les sociabilités politiques dans les bistros et les tentatives de lutter contre l'alcoolisme impulsées par les partis et syndicats). L'auteur ne cache pas ses sympathies pour les courants de gauche, critiques de la bureaucratisation du parti, mais ne néglige aucune tradition historiographique dans sa présentation.

3 La partie sur l'Autriche souligne bien quelques spécificités, en miroir du cas allemand. Outre la question des multiples nationalités, l'organisation est moins structurée, les adhésions à telle ou telle structure sont difficiles à repérer et souvent se confondent (adhérent au parti ou au syndicat, ou les deux); l'abonnement au journal socialdémocrate permet véritablement de dénombrer le milieu militant. Un autre aspect est l'engagement des femmes et du féminisme, avec des figures comme Emma Adler ou Therese Schlesinger. Enfin (et sans exclusive), la présence d'un fort courant chrétiensocial dans toute l'Autriche germanophone a créé des conditions politiques différentes de l'Allemagne pour les sociaux-démocrates.

Si l'on peut regretter que les deux espaces germanophones ne soient pas davantage mis en relation, cette petite synthèse demeure néanmoins une des rares à faire le point sur la question sociale-démocrate en croisant ces deux histoires qui, pour une large part, se confondent au cours de cette période, malgré certaines spécificités. À ce titre elle s'impose comme une bonne introduction à l'histoire sociale du monde germanophone de la fin du xIX siècle. 